\title{
Accounting Conservatism and National Culture
}

\author{
Pollyanna Gracy Wronski ${ }^{1}$ \\ falecomapolly@hotmail.com | (100000-0002-4428-7010 \\ Roberto Carlos Klann ${ }^{2}$ \\ rklann@furb.br| (1D)0000-0002-3498-0938
}

\begin{abstract}
The following study intends to evaluate the influence of Hofstede's cultural dimension (2017) on a corporation from several countries' accounting conservatism scale. Based on Thomson Reuters' data and a final sample of 54,484 observations (32 countries), the analysis was made over a period from 2010 to 2016 and was based off on Ball and Shivakumar's work (2005) in measuring accounting conservatism. When analyzing each cultural dimension individually, it was noted that companies from countries that have an individualistic culture would engage in bad accounting conservatism, while companies with a long term orientation exhibited the opposite attitude, according to the survey's scenario. In general, the conclusion is that the national culture can impact accounting information quality, impacting on a larger or lesser extent for accounting conservatism. One of the main contributions of this study is the comprehension that the intrinsic cultural factors of each nation can influence the quality of the accounting information.
\end{abstract}

\section{KEYWORDS}

Accounting Conservatism. Accounting Information Quality. National Culture. Cultural Dimensions

\footnotetext{
${ }^{1}$ Centro de Ensino Superior de Realeza, Realeza, PR, Brasil

${ }^{2}$ Universidade Regional de Blumenau, Blumenau, SC, Brasil 


\section{INTRODUCTION}

This study analyzes the influence of national culture, more specifically by look at Hofstede's cultural dimensions (2017), on the accounting conservatism level of companies from different countries. We sought to test empirically the theoretical approach draft by Gray (1988) that the culture influences accounting development, which can occur differently in each country.

Surveys that verify the countries cultural diversity in the business, companies, and accounting are proposed as greatly important by several national and international studies (Gray, 1988; Weffort, 2005; Chand, 2012; Riahi \& Omn, 2013; Kitching, Mashruwala \& Pevzner, 2016; Rodrigues et al., 2017), because they make a contribution by identifying divergences and similarities in the way accounting is performed in the countries studied.

Therefore, this study brings another perspective of analysis upon the quality of the accounting information, where focus often falls upon agency problems, dealing with an exogenous aspect of countries' cultures, and being capable of influencing the levels of accounting conservatism presented by companies around the world.

Accounting conservatism can influence accounting information quality (AIQ), improving internal control in organizations (Goh \& Li, 2011), serve as a corporate management mechanism, lower the managers' opportunistic behavior (Watts, 2003) to counterbalance the managers' optimism excess about overestimation of profits, which is more dangerous than their underestimation in terms of penalties in their disclosure (Hendriksen \& Van Breda, 1999), or to reduce the discretion and subjectivity from managers during the accounting profit disclosure (Ball, Kothari, \& Robin, 2000).

On the other hand, it can skew the recognition of facts, reducing the AIQ, because its practice increases the informational asymmetry of contracts, raising external capital costs and favoring the increase of financial constraint of companies that need to raise funds (Hendriksen \& Van Breda, 1999).

Several variables can affect the usage of the accounting conservatism in the financial statements, such as the adoption of a new accounting standard (Santana \& Klann, 2016); the votes concentration (Sarlo Neto, Rodrigo \& Almeida, 2010), because the agreement executed between the shareholders impacts on the reduction of the companies conservatism level; as well as the proper culture, since the historical development of each country, the level of the government control, the structure of the business property, in conjunction with the cultural influence received are the possible causes of the different accounting practices used by different countries (Cieslewicz, 2014).

The term 'culture' equates to a set of meanings and signs created inside a society within which individuals interact with each other. This group embraces the forms of work, leisure, housing, the language, the religion, the cuisine, the power relations, the family structure, and social systems, among others. (Chaui, 2008). According to Hofstede (1980), the culture does not consist of something that can be inherited; it is, however, obtained through a social environment that involves the individuals. It can be built, rebuilt and transformed upon the environment's needs because it does not relate with just one individual, but with all the organization that it is engaged with (Hofstede, 1980; 1991; 2001).

Accounting affects the social and cultural environments in which it takes place, and one can view the culture as a fundamental element for the comprehension of the regulations and values that govern those environments (Hopwood \& Miller, 1994). Thus, the cultural differences between the individuals can affect the relations inside of the organization; the higher the difference is, more disparate are the administrative, organizational, and strategic practices (Arińo \& De La Torre, 1998). 
BBR

17

346

According to Gray (1988), culture influences the accounting progress in companies, besides impacting on their distinct practices from country to country. The literature, in turn, recognizes the influence of the cultural factor in accounting without excluding the eventual impacts that it can cause in the financial report (Justino, Albuquerque, Quirós \& Rodrigues 2017).

This way, the divergences among countries earn space as an object of investigation and the realization of these studies become important because they allow the visualization of the environmental factors that describe the divergences in accounting (Verma, 1998). Based on the theoretical predictions that point out a relation between the national culture and the accounting, survey research was drawn up: What is the influence of national culture on the level of accounting conservatism of companies? In order to answer the survey research, this study aims to evaluate the influence of Hofstede's cultural dimensions (2017) on the level of the accounting conservatism of companies from different countries.

In general, the results indicate a high dispersion of accounting conservatism observed in the companies analyzed. Furthermore, such companies are stemming, in most cases, from countries with greater power distance, with a culture more concerned with female and collective values, with a greater aversion to uncertain situations, long-term oriented culture, and less likely to indulge. As to the cultural influence in the accounting conservatism, the results show that companies from countries that are more individualistic and with an indulgent behavior can present less conservative accounting practices, while those from countries with a more long-term oriented culture show more conservative behavior.

From a theoretical perspective, the realization of this study aims at contributing to the investigations about the AIQ, seeking to expand the limits of knowledge regarding the cultural factors that can influence the existence and level of accounting conservatism in different countries. This study sheds light on the discussion of the influence of accounting principles on the quality of accounting information, by showing that external factors, to companies, such as the country's culture, can influence the level of accounting conservatism in accounting statements of companies from different countries.

Regulatory bodies must consider this in their quest for greater comparability of accounting information internationally, as well as analysts and investors when analyzing companies from different countries. The results of this study point out that companies from different countries might present different levels of accounting information quality, even though both use international accounting standards or US accounting standards, for example.

As for the literature breakthrough, Gray's assumptions (1988) about the accounting conservatism and the national culture have already been analyzed by several authors (Schultz \& Lopez, 2001; Doupnik \& Richter, 2004; Doupnik \& Riccio, 2006; Tsakumis, 2007), but only in the form of experiments and interviews, which evaluated the interpretations and judgments by accounting professionals. This study overlaps with them, when utilizing data from accounting statements, just like Salter and Lewis (2011), who has already presented the preparers' judgment at the moment of its elaboration.

The difference between this study and Salter and Lewis' (2011) is that this one required 32 countries and took into account the six cultural dimensions of Hofstede (2017), while the former relied on 14 countries and considered just three cultural dimensions. 


\section{THEORETICAL FRAMEWORK AND HYPOTHESIS DEVELOPING}

Watts (2003) says that the practice of conservatism originated in the 19th century, since the accounting professionals had to provision all the probable loses of companies before performing any distribution of assets. However, for Basu (1997), its origin was in the 15 th century, and, even with numerous criticisms to its use, conservatism is still widely used in the last three decades (Watts, 2003).

Gray (1980) defines conservatism as the preference, when using a cautious approach, to measure future events in opposition to the competitive and optimistic market as a form of risk prevention. He forked the concept of conservatism into two sub-concept groups: conditional conservatism and unconditional conservatism (Beaver \& Ryan, 2005).

Conditional conservatism represents the skewed recognition of bad news, occurring earlier than good news (Basu, 1997; Ahmed et al., 2000; Ball et al., 2000; Ball \& Shivakumar, 2005; Brown Jr, He \& Teitel, 2006). Its use benefits the production of more transparent and loyal information to the investors, without being overly optimistic (Lopes, 2002). The asymmetric condition to the recognition of gains and losses brought by the practice benefits the users of the accounting statements, essential to mitigate the manager's opportunistic habits (Watts, 2003).

Unconditional conservatism results from the choice between two forms of measurement and recognition of events, both being equally valid, where the chosen option is the one that results in the lowest valuation of assets. It is based on uncertainty, as it affects the continuity of companies to future demands (Hendriksen \& Van Breda, 1999). In this study, the focus is on the conditional conservatism, taken from Ball e Shivakumar's model (2005).

Accounting conservatism, as a feature of AIQ, has been widely investigated in the academic environment, with researchers attempting to look at which factors determine its use. One of the first researchers to consider the culture as an important variable for the presence of conservatism among countries was Gray (1988). From theoretical conceptions, the author related conservatism to needs and desires, so that if a country aims to reduce uncertainties and be less individualistic, it will show a great tendency to be conservative.

Gray's study (1988) addressed three of the four dimensions identified by Hofstede (1980): Uncertainty Avoidance (UAI), individualism versus collectivism (IVC), and masculinity versus femininity (MAS). The author theoretically maintained that countries with higher UAI, with more collectivist and female values, were more conservative in preparing their financial statements.

To Hofstede (1980), the dimension of UAI relates to the level of social stress when facing the unknown future. Thus, this dimension is not about social behavior, but about the human search for the truth, and indicates, culturally, to what degree members of a society are comfortable or uncomfortable in different and unknown situations. When dealing with UAI, Gray (1988) claims that this dimension is the most positively related to accounting conservatism. Consequently, the preference for adopting more conservative measures ahead of profits is consistent with a scenario of high UAI $\left(\mathrm{H}_{1}\right)$, as a concern with prudence and safety leads to cautious approaches in recognizing future events.

The IVC dimension is characterized by Hofstede (1980) as the integration of individuals into primary groups and reveals the degree of integration of individuals within a group. In an individualistic organization, its members have a more competitive, more assertive view and there are no ties between its components; each one takes care of their own business and their own immediate family. On the other hand, the collectivist view, where it is noticeable an integration and cohesion among groups in society, the family vision extends to uncles, aunts, and grandparents, 
and the meaning of the collective has nothing to do with the politic sense, referring to the state, but it has a connection with the group.

One can link the individualism defined by Hofstede (1980) to the overconfidence of the individual; in other words, in societies with high IVC, more decisions are made by the individual driven by the overconfidence (Chaui, 2008).

Gray (1988) linked accounting conservatism with the IVC, noting that societies with more individualistic traits have less accounting conservatism. $\left(\mathrm{H}_{2}\right)$. This negative relation was also verified by Salter and Niswander (1995) and Salter and Lewis (2011), while Sudarwan and Fogarty (1996) observed positive relations between the IVC and the accounting conservatism derived from a study in Indonesia.

The dimension called MAS engages in, according to Hofstede (1980), the division of emotional roles between men and women, which may reflect different visions within a society. According to the author, women differ less among societies than men, of which they retain values such as modesty and affection, while men are more assertive and competitive. The assertive pole has been called "masculine" while the modest and caring has been called the "feminine" pole (Hofstede, 1998).

For Gray (1988), the MAS is negatively associated with conservatism, because masculine societies seek for more earnings, performance, and efficiency, exerting a stronger influence on the managers and statement preparers, which in this case, would tend to have a less conservative bias in the earnings measures $\left(\mathrm{H}_{3}\right)$. In line with the assumptions described by Gray (1988) are the results found by Salter and Niswander (1995) and Salter and Lewis (2011), while Sudarwan and Fogarty (1996) did not find a significative relation between these variables.

Hofstede (1980) identifies problems involving human inequality inside the power distance dimension (PDI), which reflects the extent that members with less power inside organizations accept and even expect a power that is unequally distributed. Goodwin, Goodwin, and Fiedler (2000) identified that individuals from countries with high PDI were less likely to be involved in the practice of earnings management, representing a more faithful and realistic portrayal of the company.

Almeida, Lopes, and Corrar (2011) point out that the higher the GR is, the lower the level of accounting conservatism observed. Thus, assuming a negative relationship between GR and a high PDI and a negative relationship between GR and accounting conservatism, a positive relationship between the high PDI and the accounting conservatism practice is assumed $\left(\mathrm{H}_{4}\right)$.

The fifth dimension identified by Hofstede et al. (2008), the long-term orientation versus short term orientation (LTO), relates with the choice of focus to people's efforts: the future or the present and the past. According to the authors, a society focused on cultural values that care about LTO has a forward-looking vision, saves economically, and shows values such as persistence and austerity, unlike the short-term orientation, which focuses on the past and the present.

This way, in a society, where values are short term oriented, the most important results are those perceived and evidenced in the short term. Thus, in the presented context, the higher the LTO of a country or society is, the higher the level of accounting conservatism will be presented by it $\left(\mathrm{H}_{5}\right)$.

The sixth dimension described by Hofstede, Hofstede, and Minkov (2010), indulgence versus restraint (IND), has not yet been inside the scope of studies in accounting literature involving the practice of accounting conservatism. These authors define this dimension as a tendency for individuals to allow themselves to be human figures, enjoying life. 
Linking the dimension with the practice of conservatism, it is believed that more indulgent societies, which are more likely to enjoy life, are less conservative, because according to Gray (1988), the conservatism leads to the use of prudence and caution, where the more conservative accountants opt for more cautious accounting, in order to deal with the uncertainty of future events $\left(\mathrm{H}_{6}\right)$.

Based on the above, Figure 1 presents the expected behavior for accounting conservatism in the analyzed companies to each dimension of the national culture of the countries.

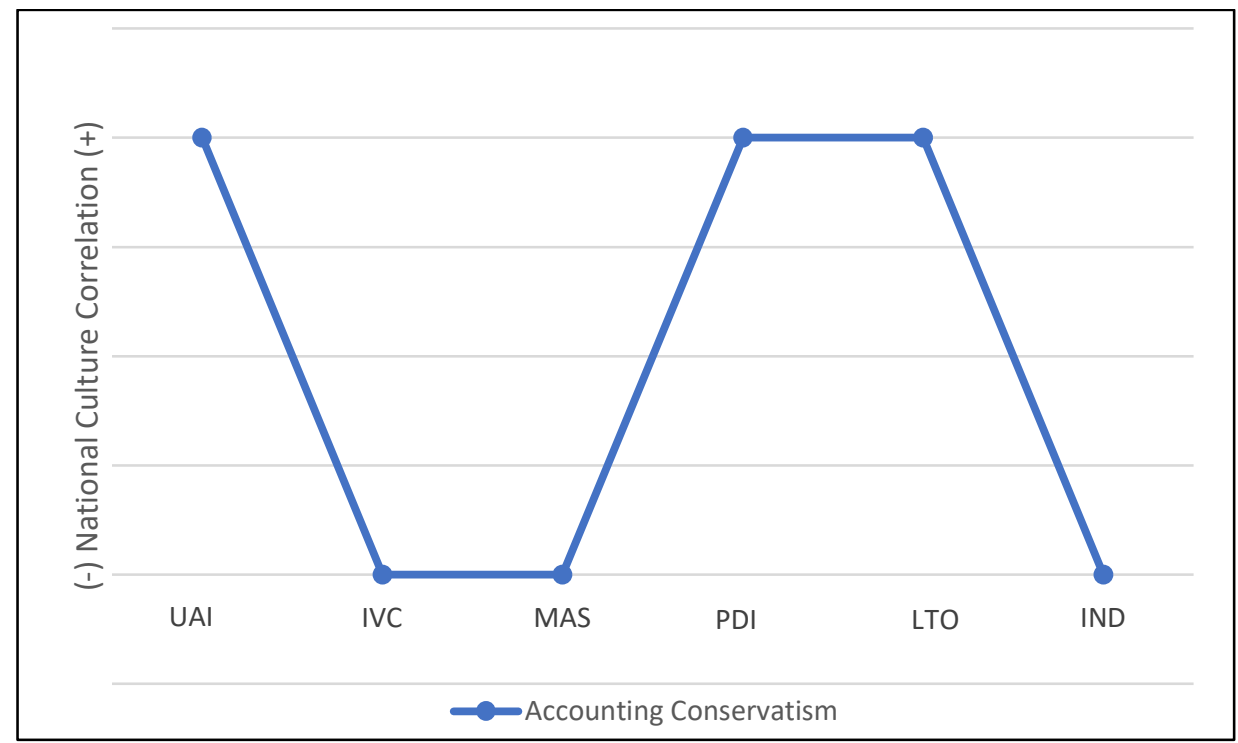

Figure 1. Conservatism and National Culture

Source: own elaboration.

We expect that the dimensions of uncertainty avoidance (UAI), power distance (PDI), and long-term orientation (LTO) are positively related to the accounting conservatism level, while individualism (IVC), masculinity (MAS) and indulgence (IND) present the opposite behavior.

However, neither the previous literature nor this study analyzes the interdependence of these cultural dimensions and its effect on the accounting conservatism. Despite this limitation, it is possible to assume that the strongest cultural dimension of a certain nation can impose itself upon others regarding the accounting conservatism.

For example, one can assume that an extremely male country, even though it has moderate cultural traits of uncertainty aversion, will tend to behave less conservatively. On the other hand, a country with a high-power distance, even though if it has individualistic traits, for example, will tend to have greater traits of accounting conservatism. Therefore, the cultural arrangement between the dimensions in each nation can be very diverse, implying possible different effects on the accounting conservatism in each country.

\section{METHODOLOGICAL PROCEDURES}

Through the Thomson Reuters ${ }^{\circledR}$ database, the study population includes 8.769 public companies from 32 countries, with data extracted from 2010 to 2016, totalizing 61.383 observations. We excluded from the sample outliers (above 3 standard-deviations) and companies with total assets less than US\$100 million, as detailed in Table 1: 
BBR

17

350
Table 1

Companies in the Sample

\begin{tabular}{lccc}
\hline Description & Companies & Observations & \% Population \\
\hline Population & 8.769 & 61.383 & $100 \%$ \\
(-) Exclusion outliers (above 3 standard-deviations) & $(29)$ & $(201)$ & $0,3 \%$ \\
(-) Companies with Total Assets < US\$ 100 million & $(942)$ & $(6.698)$ & $10,9 \%$ \\
(=) Final sample & 7.798 & 54.484 & $88,8 \%$ \\
\hline
\end{tabular}

\begin{tabular}{|c|c|c|c|c|c|c|c|}
\hline & \multirow{2}{*}{ Country } & \multicolumn{2}{|c|}{ Population } & \multicolumn{2}{|c|}{ Sample } & \multirow{2}{*}{$\%$} & \multirow{2}{*}{ \% Sample } \\
\hline & & Observations & Companies & Observations & Companies & & \\
\hline 1 & USA & 1.099 & 157 & 1.095 & 157 & $99,6 \%$ & $2,0 \%$ \\
\hline 2 & Brazil & 1.519 & 217 & 1.400 & 200 & $92,2 \%$ & $2,6 \%$ \\
\hline 3 & Canada & 5.068 & 724 & 1.808 & 259 & $35,7 \%$ & $3,3 \%$ \\
\hline 4 & Mexico & 546 & 78 & 546 & 78 & $100,0 \%$ & $1,0 \%$ \\
\hline 5 & Argentina & 280 & 40 & 254 & 37 & $90,7 \%$ & $0,5 \%$ \\
\hline 6 & Colombia & 301 & 43 & 287 & 41 & $95,3 \%$ & $0,5 \%$ \\
\hline 7 & Chile & 693 & 99 & 636 & 91 & $91,8 \%$ & $1,2 \%$ \\
\hline 8 & Peru & 616 & 88 & 582 & 84 & $94,5 \%$ & $1,1 \%$ \\
\hline 9 & China & 11.739 & 1.677 & 11.679 & 1.670 & $99,5 \%$ & $21,4 \%$ \\
\hline 10 & Japan & 1.547 & 221 & 1.537 & 220 & $99,4 \%$ & $2,8 \%$ \\
\hline 11 & India & 147 & 21 & 147 & 21 & $100,0 \%$ & $0,3 \%$ \\
\hline 12 & South Korea & 8.806 & 1.258 & 8.790 & 1.257 & $99,8 \%$ & $16,1 \%$ \\
\hline 13 & Indonesia & 1.197 & 171 & 1.136 & 163 & $94,9 \%$ & $2,1 \%$ \\
\hline 14 & Saudi Arabia & 623 & 89 & 556 & 80 & $89,2 \%$ & $1,0 \%$ \\
\hline 15 & Taiwan & 9.471 & 1.353 & 9.282 & 1.332 & $98,0 \%$ & $17,0 \%$ \\
\hline 16 & Thailand & 2.429 & 347 & 2.316 & 331 & $95,3 \%$ & $4,2 \%$ \\
\hline 17 & Philippines & 588 & 84 & 576 & 83 & $98,0 \%$ & $1,1 \%$ \\
\hline 18 & Singapore & 2.128 & 304 & 1.623 & 232 & $76,3 \%$ & $3,0 \%$ \\
\hline 19 & Nigeria & 266 & 38 & 237 & 34 & $89,1 \%$ & $0,4 \%$ \\
\hline 20 & Egypt & 322 & 46 & 292 & 42 & $90,7 \%$ & $0,5 \%$ \\
\hline 21 & South Africa & 420 & 60 & 381 & 55 & $90,7 \%$ & $0,7 \%$ \\
\hline 22 & Morroco & 98 & 14 & 91 & 13 & $92,9 \%$ & $0,2 \%$ \\
\hline 23 & Germany & 1.981 & 283 & 1.160 & 166 & $58,6 \%$ & $2,1 \%$ \\
\hline 24 & $\begin{array}{l}\text { United } \\
\text { Kingdom }\end{array}$ & 896 & 128 & 888 & 127 & $99,1 \%$ & $1,6 \%$ \\
\hline 25 & France & 2.268 & 324 & 1.294 & 185 & $57,1 \%$ & $2,4 \%$ \\
\hline 26 & Italy & 1.008 & 144 & 851 & 122 & $84,4 \%$ & $1,6 \%$ \\
\hline 27 & Russia & 1.358 & 194 & 1.357 & 194 & $99,9 \%$ & $2,5 \%$ \\
\hline 28 & Turkey & 1.127 & 161 & 1.126 & 161 & $99,9 \%$ & $2,1 \%$ \\
\hline 29 & Netherlands & 364 & 52 & 286 & 41 & $78,6 \%$ & $0,5 \%$ \\
\hline 30 & Switzerland & 686 & 98 & 592 & 85 & $86,3 \%$ & $1,1 \%$ \\
\hline 31 & Poland & 1.351 & 193 & 1.346 & 193 & $99,6 \%$ & $2,5 \%$ \\
\hline \multirow[t]{2}{*}{32} & Belgium & 441 & 63 & 333 & 48 & $75,5 \%$ & $0,6 \%$ \\
\hline & Total & 61.383 & 8.769 & 54.484 & 7.798 & $88,8 \%$ & $100 \%$ \\
\hline
\end{tabular}

Source: Survey Data. 
Table 2 shows the scores of each country in the sample, to each of the six dimensions searched by Hofstede, identified in surveys developed by the author inside the countries, through the questionnaires applied.

Table 2

Hofstede's Cultural Dimensions - Score of the countries in the sample

\begin{tabular}{|c|c|c|c|c|c|c|}
\hline Country & PDI & IVC & MAS & UAI & LTO & IND \\
\hline USA & 40 & 91 & 62 & 46 & 26 & 68 \\
\hline Brazil & 69 & 38 & 49 & 76 & 44 & 59 \\
\hline Canada & 39 & 80 & 52 & 48 & 36 & 68 \\
\hline Mexico & 81 & 30 & 69 & 82 & 24 & 97 \\
\hline Argentina & 49 & 46 & 56 & 86 & 20 & 62 \\
\hline Colombia & 67 & 13 & 64 & 80 & 13 & 83 \\
\hline Chile & 63 & 23 & 28 & 86 & 31 & 68 \\
\hline Peru & 64 & 16 & 42 & 87 & 25 & 46 \\
\hline China & 80 & 20 & 66 & 30 & 87 & 24 \\
\hline Japan & 54 & 46 & 95 & 92 & 88 & 42 \\
\hline India & 77 & 48 & 46 & 40 & 51 & 26 \\
\hline South Korea & 60 & 18 & 39 & 85 & 100 & 29 \\
\hline Indonesia & 78 & 14 & 46 & 48 & 62 & 38 \\
\hline Saudi Arabia & 95 & 35 & 60 & 80 & 36 & 52 \\
\hline Taiwan & 58 & 17 & 45 & 69 & 93 & 49 \\
\hline Thailand & 64 & 20 & 34 & 64 & 32 & 45 \\
\hline Philipinnes & 94 & 32 & 64 & 44 & 27 & 42 \\
\hline Singapore & 74 & 20 & 48 & 8 & 72 & 46 \\
\hline Nigeria & 80 & 30 & 60 & 55 & 13 & 84 \\
\hline Egypt & 70 & 25 & 45 & 80 & 7 & 4 \\
\hline South Africa & 49 & 65 & 63 & 49 & 34 & 63 \\
\hline Morroco & 70 & 46 & 53 & 68 & 14 & 25 \\
\hline Germany & 35 & 67 & 66 & 65 & 83 & 40 \\
\hline United Kingdom & 35 & 89 & 66 & 35 & 51 & 69 \\
\hline France & 68 & 71 & 43 & 83 & 63 & 48 \\
\hline Italy & 50 & 76 & 70 & 75 & 61 & 30 \\
\hline Russia & 93 & 39 & 36 & 95 & 81 & 20 \\
\hline Turkey & 66 & 37 & 45 & 85 & 46 & 49 \\
\hline Netherlands & 38 & 80 & 14 & 53 & 67 & 68 \\
\hline Switzerland & 34 & 68 & 70 & 58 & 74 & 66 \\
\hline Poland & 68 & 60 & 64 & 93 & 38 & 29 \\
\hline Belgium & 65 & 75 & 54 & 94 & 82 & 57 \\
\hline
\end{tabular}

Source: Hofstede (2017).

Measured from 0 to 100, a high score on the PDI dimension indicates how much the country accepts the distance between the members of a society/organization; the individuals expect the powerful members to guide them in their work. For this dimension, the country that achieved the highest score was Saudi Arabia (95), while Switzerland presented the lowest score. 
BBR

17

352

South Korea achieved the highest score (100) on the LTO dimension. It is necessary to highlight that the country reached the maximum score on the Hofstede's scale and according to the author, this is because Korea is one of the most pragmatic and long-term societies in the world.

The scores to the IND dimension also presented important divergences, with the country with the highest score, indicating the disposition of "enjoying life", was registered in Mexico (97), while the lowest score was Egypt (4). The score verified in Mexico indicates a definitive cultural tendency toward indulgence, which shows a desire to accomplish the impulses, showing a positive attitude, and a tendency towards optimism.

We used Ball and Shivakumar's model (2005) to measure the conditional conservatism, which measures the asymmetry of recognition between gains (good news) and losses (bad news). The model assesses the conservatism according to the occurrence of accounting earnings reversal, which allows the identification of transitional components on gains or losses. In this context, the lowest frequency of recognition of timely loss means the lowest quality of the accounting statements.

$$
\Delta N I_{i t}=\alpha_{0}+\alpha_{1} \mathrm{D} \Delta N I_{i t-1}+\alpha_{2} \Delta N I_{i t-1}+\alpha_{3} \mathrm{D} \Delta N I_{i t-1} \times \Delta N I_{i t-1}+\varepsilon_{t}
$$

In which:

$\Delta N I_{i t}$ : variation in the accounting operation profit of the company $i$ of the year $t-1$ to the $t$ weighted by total asset value at the beginning of the year $t$;

$\Delta N I_{i t-1}:$ variation in the accounting operation profit of the company $i$ of the year $t-2$ to the $t-1$ weighted by total asset value at the beginning of the year $t-1$;

$\mathrm{D} \Delta N I_{i t-1}:$ dummy variable assuming value 1 if $\Delta \mathrm{NI}_{\mathrm{it}-1}<0$, and 0 in other cases;

$\varepsilon_{t}:$ standard error of the regression.

Initially, equation 1 was run for each country, separately, in order to identify the conservatism present in the sample. According to the model, which was tested for each country, the anticipation of economic gains for when there is cash flow allows one to recognize gains as a persistent component of accounting profit, which tends not to be reversed and implies on $\alpha_{2}$ being zero. However, when the recognition of gains occurs in a timely manner, they are seen as a factor of increase in the transitional component of profit, with a tendency to be reversed in subsequent periods, which is perceived by $\alpha_{2<} 0$.

Furthermore, the recognition of losses represents earnings' transient decreases, where $\alpha_{2}+\alpha_{3}<$ 0 , and if the losses are recognized timelier than gains, it is considered as a proxy of the conditional accounting conservatism, then $\alpha_{3}<0$ (Ball \& Shivakumar, 2005). For better data visualization, we inverted the dependent variable, so in this context, $\alpha_{3}>0$ indicates conservative accounting practice.

Ball and Shivakumar's model (2005) was adjusted to measure the effect of the national culture on accounting conservatism, by the national culture variables, represented in Equation 2 by the initials CULT, representing the score of each dimension obtained by the country in the Hofstede's survey.

$$
\begin{gathered}
\Delta N I_{i t=} \alpha_{0}+\alpha_{1} \mathrm{D} \Delta N I_{i t-1}+\alpha_{2} \Delta N I_{i t-1}+\alpha_{3} \mathrm{D} \Delta N I_{i t-1} \times \Delta N I_{i t-1}+\alpha_{4} C U L T_{i t}+ \\
\alpha_{5} C U L T_{i t} \times \mathrm{D} \Delta N I_{i t-1}+\alpha_{6} C U L T_{i t} \times \Delta N I_{i t-1}+\alpha_{7} C U L T_{i t} \times \mathrm{D} \Delta N I_{i t-1} \times \Delta N I_{i t-1}+\varepsilon_{i t}
\end{gathered}
$$

Equation 2, which covers each one of the six cultural dimensions of Hofstede's sample, was tested separately for each dimension, using observations in a period from 2010 to 2016. In this 
equation, the variables of interest are $\alpha_{6}$ and $\alpha_{7}$. The identification of the timely recognition of economic losses related to each cultural dimension implies their recognition with a decrease in transient profits verified at $\alpha_{6}+\alpha_{7}<0$. The hypothesis of the existence of conservatism related to each one of the cultural dimensions tested, which indicates that the economic losses are recognized faster than the gains, results in $\alpha_{7}<0$. Thus, $\alpha_{6}$ refers to the early recognition of gains and $\alpha_{7}$ to the relation between the accounting conservatism and the cultural dimension surveyed.

For control variables, IFRS was used (1 for adopting companies and zero otherwise) and size (log of Total Assets). The IFRS adoption by countries may influence the level of companies accounting conservatism; therefore, it would be prudent, when comparing such levels among the companies of the sample, to consider a possible effect of the IFRS. As for the size, it is a common control variable in accounting conservatism studies.

\section{RESULTS AND DISCUSSIONS}

\subsection{DesCriptive STATISTICS}

Initially, the descriptive statistics of the Net Income (NI) and Total Assets (TA) variables, used in Ball e Shivakumar's model (2005), in addition to the national culture variables, represented by Hofstede's cultural dimensions: power distance (PDI), individualistic versus collectivistic (IVC), masculine versus feminine (MAS), uncertainty avoidance (UAI), long term orientation versus short term orientation (LTO) and indulgence versus restraint (IND), as shows the Table 3:

Table 3

Descriptive statistics of the study's variables

\begin{tabular}{lccccc}
\hline Variable & Observations & Average & Standard Deviation & Minimum & Maximum \\
\hline NI (in millions \$) & 54.484 & 459 & 17.074 & -45.560 & 1.651 .000 \\
TA (in millions \$) & 54.484 & 5.544 & 190.363 & 0,0001 & 17.050 .000 \\
$\Delta \mathrm{NI}_{\mathrm{it}}$ & 54.484 & 0,1384 & 0,1741 & $-7,7243$ & 7,3173 \\
$\mathrm{D} \Delta \mathrm{NI}_{\mathrm{it}-1}-\alpha 1($ dummy) & 54.484 & 0,4353 & - & 0 & 1 \\
$\Delta \mathrm{NI}_{\mathrm{it}-1}-\alpha 2$ & 54.484 & 0,123 & 0,4121 & $-50,3689$ & 45,0253 \\
$\mathrm{D} \Delta \mathrm{NI}_{\mathrm{it}-1} * \mathrm{NI}_{\mathrm{it}-1}-\alpha 3$ & 54.484 & 0,0081 & 0,0901 & $-2,1178$ & 5,7973 \\
$\mathrm{PDI}$ & 54.484 & 64,8577 & 17,2174 & 34 & 95 \\
$\mathrm{IVC}$ & 54.484 & 31,8028 & 22,1399 & 13 & 91 \\
$\mathrm{MAS}$ & 54.484 & 52,5225 & 14,0807 & 14 & 95 \\
$\mathrm{UAI}$ & 54.484 & 62,0197 & 23,936 & 8 & 95 \\
LTO & 54.484 & 73,5542 & 25,9956 & 7 & 100 \\
$\mathrm{IND}$ & 54.484 & 40,7075 & 16,1610 & 4 & 97 \\
\hline
\end{tabular}

Graphic subtitle: NI: Net Income; TA: Total Assets; $\Delta \mathrm{NI}_{\mathrm{it}}$ variation in accounting net incoming of the company $i$ of the year $t-1$ to the $t$ weighted by the total asset value at the beginning of the year $t ; \mathrm{D}_{\Delta \mathrm{NI}_{\mathrm{it}-1}}$ : dummy for the variation of the company's net accounting profit $i$ of the year $t-1$ to the year $\mathrm{t}$, if indicates negative variation, assumes value 1 if $\Delta \mathrm{NI}_{\mathrm{it}}<0$, and 0 to other cases;: variation in accounting net income of the company $i$ of the year $t-2$ to the $t-1$ weighted by the total asset value at the beginning of the year $t-1$.

Source: Survey data.

There is a positive variation in the net income $\left(\Delta \mathrm{NI}_{\mathrm{i}}\right)$ over the period analyzed, which indicates that corporate profitability has been improving at the period, even with a present discrepancy among the companies (higher than average standard deviation). The variables Net Incoming 
BBR

17

354

(NI) and Total Asset (TA) were used to calculate the $\Delta \mathrm{NI}_{\mathrm{it}}$ and show high dispersion, which is understandable given that the data come from companies from 32 countries and nine different sectors.

The variable $\mathrm{D} \Delta \mathrm{NI}_{\mathrm{it}-1}$ indicates that about $44 \%$ of the searched companies show a negative variation on the reported profit, which is in line with the positive average found to the profit variation $\left(\Delta \mathrm{NI}_{\mathrm{it}}\right)$, as the majority of the companies $(56 \%)$ found positive variation in their earnings in the period analyzed.

The variable $\left(\mathrm{D} \Delta \mathrm{NI}_{\mathrm{it}-1}{ }^{*} \Delta \mathrm{NI}_{\mathrm{it}-1}\right)$ designates the level of conservatism adopted by the companies, as observed by the coefficient $\alpha_{3}$ of Ball \& Shivakumar's conservatism model (2005). The average of the conservatism variable was 0,0081 , with a higher standard deviation comparing to the average, indicating high dispersion of the data.

The scores of Hofstede's cultural dimensions shows less discrepancy, based on the average of cultural variables, which can represent that companies come from most countries with higher PDI, with a culture that is more concerned with female and collective values, with greater aversion to situations of uncertainty, which reveals bigger concern with the future, and maintains a longterm orientated culture and with less aptness to enjoy life (less score to indulgence).

We performed Pearson and Spearman's correlation tests, as shown in Table 4:

Table 4

Pearson (below diagonal) and Spearman (above diagonal) correlation analysis

\begin{tabular}{lcccccccccccc}
\hline & NI & TA & $\Delta N I i t$ & $\alpha 1$ & $\alpha 2$ & $\alpha 3$ & PDI & IVC & MAS & UAI & LTO & \multicolumn{1}{c}{ IND } \\
\hline NI & 1 & $\mathbf{0 , 5 8 0}$ & $\mathbf{0 , 2 4 9}$ & $\mathbf{- 0 , 2 1 7}$ & $\mathbf{0 , 1 2 5}$ & $\mathbf{0 , 0 5 7}$ & $-0,003$ & $\mathbf{0 , 0 3 0}$ & $-\mathbf{0 , 1 5 5}$ & $\mathbf{0 , 2 5 4}$ & $\mathbf{0 , 0 3 6}$ & $\mathbf{- 0 , 0 4 9 7}$ \\
TA & $\mathbf{0 , 8 8 4}$ & 1 & $\mathbf{- 0 , 0 3 8}$ & $\mathbf{0 , 0 2 6}$ & $\mathbf{- 0 , 0 3 6}$ & $\mathbf{- 0 , 0 1 3}$ & $\mathbf{- 0 , 0 2 8}$ & $-0,008$ & $-\mathbf{0 , 3 0 3}$ & $\mathbf{0 , 4 3 1}$ & $\mathbf{0 , 1 4 4}$ & $\mathbf{- 0 , 1 0 7 2}$ \\
$\Delta$ NI $_{\text {it }}$ & $-0,000$ & $-0,003$ & 1 & $\mathbf{- 0 , 8 5 4}$ & $\mathbf{- 0 , 0 8 9}$ & $\mathbf{- 0 , 1 3 6}$ & $\mathbf{0 , 0 1 0}$ & $\mathbf{0 , 0 0 9}$ & $\mathbf{0 , 0 3 7}$ & $\mathbf{- 0 , 0 3 2}$ & $\mathbf{- 0 , 0 1 6}$ & $-0,002$ \\
a1 & $-0,001$ & 0,006 & $\mathbf{- 0 , 3 2 7}$ & 1 & $\mathbf{0 , 0 4 7}$ & $\mathbf{0 , 1 4 1}$ & $\mathbf{- 0 , 0 1 6}$ & $\mathbf{- 0 , 0 2 4}$ & $-\mathbf{0 , 0 4 7}$ & $\mathbf{0 , 0 4 0}$ & $\mathbf{0 , 0 2 8}$ & 0,0064 \\
a2 & $-0,001$ & $-0,001$ & $\mathbf{0 , 0 4 8}$ & $\mathbf{0 , 0 1 4}$ & 1 & $\mathbf{0 , 6 0 4}$ & $\mathbf{0 , 0 2 6}$ & $\mathbf{- 0 , 0 1 2}$ & $\mathbf{0 , 0 3 7}$ & $\mathbf{- 0 , 0 4 4}$ & 0,004 & $\mathbf{- 0 , 0 1 9 9}$ \\
a3 & $-0,003$ & $-0,004$ & $\mathbf{- 0 , 1 9 8}$ & $\mathbf{0 , 1 0 3}$ & $\mathbf{0 , 2 1 8}$ & 1 & $\mathbf{- 0 , 0 1 2}$ & $\mathbf{- 0 , 0 1 9}$ & $\mathbf{- 0 , 0 0 9}$ & 0,003 & $\mathbf{0 , 0 1 2}$ & $\mathbf{0 , 0 1 3 6}$ \\
PDI & $\mathbf{0 , 0 4 7}$ & $\mathbf{0 , 0 4 9}$ & $-0,000$ & $-0,007$ & $\mathbf{0 , 0 1 1}$ & $-0,008$ & 1 & 0,003 & $\mathbf{0 , 1 5 9}$ & $\mathbf{- 0 , 2 8 3}$ & $\mathbf{- 0 , 1 8 3}$ & $\mathbf{- 0 , 6 2 0 9}$ \\
IVC & $\mathbf{0 , 0 1 3}$ & 0,014 & $\mathbf{- 0 , 0 1 5}$ & $-0,008$ & $\mathbf{- 0 , 0 1 9}$ & $-0,004$ & $\mathbf{- 0 , 5 2 4}$ & 1 & $\mathbf{0 , 4 0 6}$ & $\mathbf{- 0 , 0 5 4}$ & $\mathbf{- 0 , 6 4 7}$ & $\mathbf{0 , 1 0 7 2}$ \\
MAS & $\mathbf{- 0 , 0 2 8}$ & $-0,03$ & $\mathbf{0 , 0 1 1}$ & $\mathbf{- 0 , 0 4 2}$ & 0,002 & $-0,004$ & $\mathbf{0 , 0 9 9}$ & 0,28 & 1 & $\mathbf{- 0 , 5 2 4}$ & $\mathbf{- 0 , 2 5 6}$ & $\mathbf{- 0 , 1 3 8 1}$ \\
UAI & $\mathbf{0 , 0 3 3}$ & 0,036 & $\mathbf{- 0 , 0 1 4}$ & $\mathbf{0 , 0 3 6}$ & $\mathbf{- 0 , 0 0 9}$ & $-0,001$ & $\mathbf{- 0 , 2 8 2}$ & 0,070 & $-0,293$ & 1 & $\mathbf{0 , 2 0 1}$ & $\mathbf{0 , 1 6 8 4}$ \\
LTO & 0,004 & 0,004 & $\mathbf{0 , 0 0 8}$ & $\mathbf{0 , 0 1 3}$ & $\mathbf{0 , 0 1 1}$ & $-0,005$ & $\mathbf{0 , 0 6 5}$ & $-0,493$ & $-0,038$ & $-0,014$ & 1 & $\mathbf{- 0 , 3 2 0 8}$ \\
IND & $\mathbf{- 0 , 0 2 9}$ & $-0,031$ & 0,006 & $-0,006$ & $\mathbf{- 0 , 0 1 1}$ & $\mathbf{0 , 0 0 9}$ & $\mathbf{0 , 5 1 1}$ & 0,439 & $-0,080$ & 0,129 & $-0,546$ & 1 \\
\hline
\end{tabular}

Obs.: bold numbers significant to $95 \%$.

Source: Survey Data

The highest Pearson's correlation coefficient between those cultural dimensions is between the variables PDI and IVC $(-0,5239)$ and PDI and IND $(0,511)$. The correlation found, below 0,6, can be considered weak; it indicates that more individualistic cultures accept less power concentration, while cultures that accept such concentration show aspects of enjoying life (indulgence).

As for Spearman's correlation, the most expressive coefficients were between the LTO and IVC $(-0,6471)$ and IND and PDI $(-0,6209)$ variables, both considered moderate. It indicates that more individualistic cultures have a shorter-term vision, and more indulgent cultures would not accept power concentration. 


\subsection{IDENTIFICATION OF THE LEVEL OF ACCOUNTING CONSERVATISM IN COMPANIES}

Before identifying the level of the accounting conservatism, we ran assumption tests of regression models such as multicollinearity (Variance Inflation Factors-VIF) and heteroscedasticity (Modified Wald's Test). The first one was attended, with factors ranging from 1,01 to 1,06. The second one pointed to a problem of heteroscedasticity, adjusted with regression by robust errors. All the regressions (OLS) were performed by controlling the fixed effects of industry (sector), country, and year. The results are in Table 5:

Table 5

Results of the original accounting conservatism model and the addition of control variables company size and IFRS adoption

\begin{tabular}{|c|c|c|c|c|}
\hline Variables & Expected Signal & Model 1 & Model 2 & Model 3 \\
\hline \multirow[t]{2}{*}{$\mathrm{D} \Delta \mathrm{NI}_{\mathrm{it}-1}$} & $+/-$ & $-0.025^{* * *}$ & $-0.048^{* * *}$ & $-0.029^{* * *}$ \\
\hline & & $(0.003)$ & (0.009) & $(0.003)$ \\
\hline \multirow[t]{2}{*}{$\Delta \mathrm{NI}_{\mathrm{it}-1}$} & + & $-0.095^{* * *}$ & $-0.351^{* * *}$ & $-0.150^{* * *}$ \\
\hline & & $(0.034)$ & $(0.116)$ & $(0.013)$ \\
\hline \multirow[t]{2}{*}{$\mathrm{D} \Delta \mathrm{NI}_{\mathrm{it}-1}{ }^{*} \Delta \mathrm{NI}_{\mathrm{it}-1}$} & + & $0.140^{* * *}$ & $0.294^{* *}$ & $0.162^{* * *}$ \\
\hline & & $(0.045)$ & $(0.123)$ & $(0.016)$ \\
\hline \multirow[t]{2}{*}{ CONTR } & $+/-$ & & 0.000 & $-0.023^{* * *}$ \\
\hline & & & $(0.000)$ & $(0.004)$ \\
\hline \multirow{2}{*}{$\mathrm{CONTR}^{*} \mathrm{D} \Delta \mathrm{NI}_{\mathrm{it}-1}$} & $+/-$ & & $0.003^{* * *}$ & $0.015^{* * *}$ \\
\hline & & & $(0.001)$ & $(0.005)$ \\
\hline \multirow[t]{2}{*}{ CONTR * $\Delta \mathrm{NI}_{\mathrm{it}-1}$} & + & & $0.029^{* *}$ & $0.114^{* * *}$ \\
\hline & & & $(0.014)$ & $(0.038)$ \\
\hline \multirow[t]{2}{*}{$\mathrm{CONTR}^{*} \mathrm{D} \Delta \mathrm{NI}_{\mathrm{it}-1}{ }^{*} \Delta \mathrm{NI}_{\mathrm{it}-1}$} & + & & -0.015 & 0.081 \\
\hline & & & $(0.015)$ & $(0.062)$ \\
\hline \multirow[t]{2}{*}{ Constant } & $+/-$ & -0.007 & $-0.034^{* *}$ & -0.008 \\
\hline & & $(0.005)$ & $(0.013)$ & $(0.005)$ \\
\hline \multicolumn{2}{|l|}{ Observations } & 54,484 & 54,484 & 54,484 \\
\hline \multicolumn{2}{|l|}{$\mathrm{R}^{2}$} & 0.042 & 0.067 & 0.066 \\
\hline \multicolumn{2}{|l|}{ FE sector-country-year } & Yes & Yes & Yes \\
\hline
\end{tabular}

Robust standard errors in parentheses; ${ }^{* * *} \mathrm{p}<0.01,{ }^{* *} \mathrm{p}<0.05,{ }^{*} \mathrm{p}<0.1$

Model 1: Original; Model 2: with variable control of company size; Model 3: with variable IFRS control. Graphic Subtitle: $\Delta \mathrm{NI}_{\text {it: }}$ variation in accounting net incoming of the company $i$ of the year $t-1$ to the $t$ weighted by the total asset value at the beginning of the year $t ; \mathrm{D} \Delta \mathrm{NI}_{\mathrm{it}-1}$ : dummy for the variation of the company's net accounting profit $i$ of the year $t-1$ to the year $\mathrm{t}$, if indicates negative variation, assumes value 1 if $\Delta \mathrm{NI}_{\mathrm{it}}<0$, and 0 to other cases:: variation in accounting net income of the company $i$ of the year $t-2$ to the $t-1$ weighted by the total asset value at the beginning of the year $t-1$.CONTR: variable of size control (Total Asset-TA) and IFRS.

Source: Survey data.

As shown in Table 5, there is a tendency for the companies in the sample to recognize economic losses more quickly than gains. We observe this tendency as a result of the transience of gains through the coefficient $\alpha_{3}(0,140)$, the significance of the $\alpha_{2}$ and $\alpha_{3}$ coefficients, which allows statistical confirmation of the conservative behavior of these companies. 
BBR

17

To further analyze accounting conservatism in companies, we insert the size of the company (log AT) and the IFRS adoption as control variables in the model proposed by Ball and Shivakumar (2005). In both cases, the results related to conservatism $\left(\alpha_{3}\right)$ are consistent with the original sample, with a positive and significant relation, although $\alpha_{7}$ was not significant, it is not possible to infer the influence of the size and the IFRS adoption on the companies conservatism level.

\subsection{ANALYSIS OF THE RELATION BETWEEN THE DIMENSIONS OF NATIONAL CULTURE AND ACCOUNTING CONSERVATISM}

In general, according to Salter \& Lewis (2011), accounting conservatism may be related to the differences between countries, which can come from differences in cultural values. Salter and Lewis' study (2011) corroborates the assumptions of Gray (1988) and Doupnik \& Tsakumis (2004), who present that culture is related to more conservative application of accounting rules in financial statements.

Thus, we present in Table 6 an individual analysis of the influence of each Hofstede's cultural dimensions (2017).

Table 6

Results of the relation between accounting conservatism and cultural dimension

\begin{tabular}{|c|c|c|c|c|c|c|}
\hline Variables & Model 1 & Model 2 & Model 3 & Model 4 & Model 5 & Model 6 \\
\hline \multirow[t]{2}{*}{$\mathrm{D} \Delta \mathrm{NI}_{\mathrm{it}-1}$} & $-0.013^{*}$ & $-0.026^{* * *}$ & $-0.050^{* * *}$ & $-0.057^{* * *}$ & $-0.044^{* * *}$ & 0.001 \\
\hline & $(0.007)$ & $(0.005)$ & $(0.012)$ & $(0.010)$ & $(0.006)$ & $(0.007)$ \\
\hline \multirow[t]{2}{*}{$\Delta \mathrm{NI}_{\mathrm{it}-1}$} & -0.116 & $-0.182^{* * *}$ & $-0.226^{* * *}$ & $-0.224^{* * *}$ & $-0.154^{* * *}$ & -0.074 \\
\hline & $(0.075)$ & $(0.050)$ & $(0.054)$ & $(0.103)$ & $(0.055)$ & $(0.053)$ \\
\hline \multirow[t]{2}{*}{$\mathrm{D} \Delta \mathrm{NI}_{\mathrm{it}-1}{ }^{*} \Delta \mathrm{NI}_{\mathrm{it}-1}$} & 0.127 & $0.247^{* * *}$ & 0.311 & 0.173 & 0.035 & $0.463^{* * *}$ \\
\hline & $(0.117)$ & $(0.079)$ & $(0.215)$ & $(0.137)$ & $(0.084)$ & $(0.141)$ \\
\hline \multirow[t]{2}{*}{ CULT } & 0.000 & 0.000 & 0.001 & $-0.001^{* * *}$ & $0.000^{* * *}$ & $0.001^{* *}$ \\
\hline & $(0.000)$ & $(0.000)$ & $(0.001)$ & $(0.000)$ & $(0.000)$ & $(0.000)$ \\
\hline \multirow{2}{*}{$\mathrm{CULT}^{*} \mathrm{D} \Delta \mathrm{NI}_{\mathrm{it}-1}$} & $0.000^{*}$ & 0.000 & $0.001^{* *}$ & $0.001^{* * *}$ & $0.000^{* * *}$ & $0.000^{* * *}$ \\
\hline & $(0.000)$ & $(0.000)$ & $(0.000)$ & $(0.000)$ & $(0.000)$ & $(0.000)$ \\
\hline \multirow[t]{2}{*}{$\mathrm{CULT}^{*} \Delta \mathrm{NI}_{\mathrm{it}-1}$} & 0.000 & $0.004^{* *}$ & $0.003^{* * *}$ & 0.002 & 0.001 & 0.000 \\
\hline & $(0.001)$ & $(0.002)$ & $(0.001)$ & $(0.001)$ & $(0.001)$ & $(0.001)$ \\
\hline \multirow{2}{*}{$\mathrm{CULT}^{*} \mathrm{D} \Delta \mathrm{NI}_{\mathrm{it}-1}{ }^{*} \Delta \mathrm{NI}_{\mathrm{it}-1}$} & 0.000 & $-0.004^{* *}$ & -0.004 & 0.000 & $0.004^{* *}$ & $-0.005^{* *}$ \\
\hline & $(0.002)$ & $(0.002)$ & $(0.004)$ & $(0.002)$ & $(0.002)$ & $(0.002)$ \\
\hline \multirow[t]{2}{*}{ Constant } & -0.003 & -0.044 & -0.060 & $0.028^{* *}$ & 0.006 & $-0.075^{* *}$ \\
\hline & $(0.010)$ & $(0.028)$ & $(0.037)$ & $(0.014)$ & $(0.008)$ & $(0.029)$ \\
\hline \multirow{3}{*}{$\begin{array}{l}\text { Observations } \\
\mathrm{R}^{2} \\
\text { FE sector-country-year }\end{array}$} & 54,484 & 54,484 & 54,484 & 54,484 & 54,484 & 54,484 \\
\hline & 0.042 & 0.048 & 0.049 & 0.045 & 0.060 & 0.055 \\
\hline & Yes & Yes & Yes & Yes & Yes & Yes \\
\hline
\end{tabular}

Robust standard errors in parentheses; ${ }^{* * *} \mathrm{p}<0.01,{ }^{* *} \mathrm{p}<0.05,{ }^{*} \mathrm{p}<0.1$

Graphic Subtitle: CULT: cultural dimensions; UAI: score of cultural dimension of uncertainty avoidance (Mod. 1); IVC: individualistic versus collectivistic (Mod. 2); MAS: score of cultural dimension of masculine versus feminine (Mod. 3); PDI: score of cultural dimension of power distance (Mod. 4); LTO: score of cultural dimension of longterm orientation versus short-term orientation (Mod. 5); IND: score of cultural dimension of indulgence versus restraint (Mod. 6).

Source: Survey data. 
The results show the existence of a positive relationship between the UAI and accounting conservatism. However, it is not fair to say that the UAI can influence it, as $\alpha_{7}$ is not significant. The same happens with coefficient $\alpha_{6}$, which deals with the early recognition of gains, so it is not significant either.

This result goes against Gray's study (1988), which points out that accounting conservatism can be related to the UAI, because the preference for more conservative accounting in profit measurement is consistent with the strong UAI, due to a concern with security and the need to adopt a cautious stance when dealing with the uncertainties of future events.

About $\mathrm{H}_{1}$, which assumes a positive relationship between the cultural dimension UAI and the practice of accounting conservatism, the results allowed us to reject the hypothesis. This finding is the opposite of that observed by Salter and Niswander (1995), Sudarwan and Fogarty (1996), Schultz and Lopez (2001), and Lima et al. (2016). However, it is important to say that those surveys were biased, usually, on the auditor's and accountants' opinions, rather than working with conservatism data directly.

Regarding the results of the relation between the conservatism and the IVC dimension, the coefficient $\alpha_{7}(-0,0038)$ indicates a negative relation between the variables with the significance of $5 \%$, allowing to infer that the less individualistic companies are, the bigger is the level of accounting conservatism.

These results do not corroborate those found by Gray (1988), who says that companies in less individualistic countries show more accounting conservatism. On the other hand, they are the opposite to those found by Salter and Lewis' survey (2011), which confirmed a strong positive relationship between the corporate values of IVC and the unconditional conservatism. However, we should consider that in this study, the conditional conservatism was the one approached, different from the Salter and Lewis' study (2011), which may justify the contradictory results found.

Regarding $\mathrm{H}_{2}$, that expected a negative relation between the IVC and the accounting conservatism; the results do not allow us to reject the $\mathrm{H}_{2}$, which does not corroborate the studies of Doupnik and Tsakumis (2004) and Salter \& Lewis (2011), as well as Gray's (1988). However, when excluding Chinese, South Korean, and Taiwanese companies, the relation becomes positive, indicating that companies from more individualistic countries would be more conservative, which goes against the theoretical prediction. This result was also found by Sudarwan and Fogarty (1996) with Indonesian companies, a country with a low level of IVC in an environment of accounting standards changing.

For the MAS construct, the results of Table 6 indicate a negative relation between the accounting conservatism and companies from countries with more masculine cultural features $\left(\alpha_{7}=-0,0036\right)$; nevertheless, without statistical significance. The coefficient $\alpha_{6}(-0,003)$, significant to $1 \%$, allows identifying a negative relation between the MAS and the early recognition of earnings, which can be explained by the own limitation imposed many times by the accounting standards.

According to Gray (1988), the MAS shows a negative relation with the conservatism, as the companies from more culturally masculine countries present more competitively and look for more earnings and more performance, which implies a bigger influence on the managers and financial statements preparers, that would theoretically result in a tendency to present a less conservative bias in the income statement. However, we cannot confirm such relationship in this study. 
BBR

17

358

The negative relationship between the MAS and the conservatism, as expected in $\mathrm{H}_{3}$ was rejected, due to the coefficient not presenting significance, except from the model in which we captured the variable MAS through a dummy (> $50=1)$. This result does not corroborate Gray's propositions (1988) and Salter and Niswander's study (1995), pointing out that feminine societies are more conservatives than masculine ones.

Regarding the relation between conservatism and the PDI, we expected a positive relation, so that the bigger the accounting conservatism presented by the companies in the survey is, the bigger would be the PDI level observed.

When relating the conservatism with the PDI, through analysis of coefficient $\alpha_{7}$ (Table 6 ) it is not possible to confirm the relation expected, due to the lack of statistical significance and the contrary signal presented by the coefficient. The same happens when analyzing the coefficient $\alpha_{6}$, which is positive, confirming the relation expected, but without any statistical significance.

To the PDI, we expected a positive relationship with accounting conservatism, as described in $\mathrm{H}_{4}$. However, the results of the study led to the rejection of the hypothesis, due to the nonexistence of the statistical significance among the variables, as well as the contrary signal of the coefficient. This result encounters with Sudarwan and Fogarty's studies (1996), made in Indonesia, a country that has a high score for PDI (78); as well as the survey of Lima et al. (2016), with Brazilians accounting operators, that also presented a high level of this dimension (69).

We confirmed the expected positive relationship between the LTO and the level of accounting conservatism, by the analysis of the coefficient $\alpha_{7}(0,0038)$ that proves significant to $5 \%$. The analysis of the coefficient $\alpha_{6}(0,0010)$, however, does not confirm the positive relation of the dimension with the early recognition of gains, because the coefficient is not statistically relevant. The results of the survey corroborate those found by Radebaugh and Gray (2002), which pointed out that accounting conservatism is influenced positively by this cultural dimension.

As for the LTO, as expressed by the hypothesis $\mathrm{H}_{5}$, was expected to be a positive relation. Only when we excluded companies from China, South Korea, and Taiwan, the result did not appear significative. The previous studies have not related LTO with the accounting conservatism. Therefore, this result is important insofar as it empirically tests a theoretical proposition and, at least for the total sample, finds empirical confirmation.

According to Hofstede, Hofstede, and Minkov (2010), indulgence involves a tendency for individuals in a society to indulge in human design, enjoying life. Societies with higher scores in this dimension tend to be less conservative. Thus, from the analysis of the $\alpha_{7}(-0,004)$ coefficient, the researched sample confirms the expected effect, so that IND is negatively associated with accounting conservatism, with a statistical significance of $5 \%$.

For the last dimension tested in the study, the IND, we expected a negative relation with accounting conservatism, according to $\mathrm{H}_{6}$. Based on the results, we cannot reject $\mathrm{H}_{6}$ (except for the models with control variables in Table 5, that did not prove to be significant), confirming the theoretical prediction that companies from more indulgent societies adopt accounting practices which are less conservative.

In general, we can infer that companies from more individualistic and indulgent countries may have less conservative accounting practices, while those from countries with higher LTO culture exhibit the opposite (more conservative) behavior. 


\section{FINAL CONSIDERATIONS}

The present study had a goal to evaluate the influence of Hofstede's cultural dimensions (2017)

on the level of accounting conservatism of companies from different countries. To this end, we researched 7.798 companies and 54.484 observations extracted from 32 countries.

This study sought empirical evidence that could contribute to the reflection and discussion on AIQ. Understanding how conservatism appears in financial statements is important because it assists in the economic and financial analysis of companies, contributes to the regulatory processes of accounting, and promotes the issuance of higher quality financial statements.

In general, through the findings and corroborating the literature, we conclude that cultural factors from country to country do influence accounting information. Specifically, in the case of this study, certain cultural dimensions, especially IVC, LTO, and IND are related to accounting conservatism, the former positively, and the latter negatively.

One of the main implications of this study is that the comparability of the companies financial statements from different countries may not be a simple task to achieve, even if accounting standards such as IFRS is used due to cultural differences among countries, affecting the AIQ.

Another important implication of the study is that the analysis of accounting quality at the international level, specifically in the case of the accounting conservatism, has to take into account the cultural factors of each country, which should be considered by the respective national regulatory bodies, in order to produce accounting principles more appropriate to the reality of each nation.

Finally, it is important to highlight that this study has its limitations. The first one is the assumption of perennial national culture. This way, as recommendations for future studies, it may be interesting to consider that a country's national culture may change in the long-term. Thus, studies with longer time horizons could identify countries' cultural changes and how this would affect a long-term AIQ.

Another limitation of this study is that it does not consider regional differences within each country. Thus, a point to be discussed in future research is the condition that, even within a single country, different cultures may exist, and these may influence accounting conservatism differently.

\section{REFERENCES}

Almeida, J. E. F., Lopes, A. B., \& Corrar, L. J. (2011). Gerenciamento de resultados para sustentar a expectativa do mercado de capitais: impactos no índice market-to-book. Advances in Scientific and Applied Accounting, 4(1), 44-62.

Ariño, A., \& De La Torre, J. (1998). Learning from failure: Towards an evolutionary model of collaborative ventures. Organization Science, 9(3), 306-325.

Ball, R., \& Shivakumar, L. (2005). Earnings quality in UK private firms: comparative loss recognition timeliness. Journal of Accounting and Economics, 39(1), 83-128.

Basu, S. (1997). The conservatism principle and the asymmetric timeliness of earnings1. Journal of Accounting and Economics, 24(1), 3-37.

Beaver, W. H., \& Ryan, S. G. (2005). Conditional and unconditional conservatism: Concepts and modeling. Review of Accounting Studies, 10(2-3), 269-309.

Brown JR. W. D., He, H., \& Teitel, K. (2006). Conditional conservatism and the value relevance of accounting earnings: An international study. European Accounting Review, 15(4), 605-626. 
BBR

17

360

Cieslewicz, J. K. (2014). Relationships between national economic culture, institutions, and accounting: Implications for IFRS. Critical Perspectives on Accounting, 25(6), 511-528.

Chand, Parmod. (2012). The effects of ethnic culture and organizational culture on judgments of accountants. Advances in Accounting, 28(2), 298-306.

Chaui, M. (2008). Cultura y democracia. Le Monde diplomatique en español, (153), 25-26.

Doupnik, T. S., \& Richter, M. (2004). The impact of culture on the interpretation of "in context" verbal probability expressions. Journal of International Accounting Research, 3(1), 1-20.

Doupnik, T. S., \& Tsakumis, G. T. (2004). A critical review of tests of Gray's theory of cultural relevance and suggestions for future research. Journal of Accounting Literature, 23, 1-48.

Doupnik, T. S., \& Riccio, E. L. (2006). The influence of conservatism and secrecy on the interpretation of verbal probability expressions in the Anglo and Latin cultural areas. The International Journal of Accounting, 41(3), 237-261.

Goh, B. W., \& Li, D. (2011). Internal controls and conditional conservatism. The Accounting Review, 86 (3), 975-1005.

Goodwin, J. D., Goodwin, D., \& Fiedler, B. (2000). The influence of culture on accountants' ethical decision making in Singapore and Australia. Accounting Research Journal, 13(2), 22-36.

Gray, S. J. (1988). Towards a theory of cultural influence on the development of accounting systems internationally. Abacus, 24(1), 1-15.

Hendriksen , E. S., \& Van Breda, M. F. (1999). Teoria da contabilidade. Atlas.

Hofstede, G. (1980). The cultural relativity of organizational practices and theories. Journal of International Business Studies, 14(2), 75-89.

Hofstede, G. (1991). Organizations and cultures: Software of the mind. McGrawHill.

Hofstede, G. (1997). Riding the waves: A rejoinder. International Journal of Intercultural Relations, 2(21), 287-290.

Hofstede, G. H. et al. (Eds). (1998). Masculinity and femininity: The taboo dimension of national cultures. Thousand Oaks, CA: Sage.

Hofstede, G. et al. (2008). Values survey module 2008 manual. Maastricht: Institute for Research on Intercultural Cooperation. http://geerthofstede.com/research-and-vsm/vsm-08/

Hofstede, G. (2010). Geert Hofstede. National cultural dimensions. Recuperado em 23 maio, 2017, de https://www.hofstede-insights.com/models/national-culture/.

Hofstede, G., Hofstede, G. J., \& Minkov, M. (2010). Cultures et organizations: Nos programmations mentales. Pearson Education France.

Hofstede, G. Country comparison. http://www.hofstede-insights.com/country-comparison

Hopwood, A. G., \& Miller, P. (Eds.). (1994). Accounting as social and institutional practice. Cambridge University Press.

Lima, B. J. (2016). O impacto das dimensões culturais sobre a prática contábil no brasil: um olhar a partir da percepção dos operadores da contabilidade. Revista de Educação e Pesquisa em Contabilidade, 10(4), 353-370.

Justino, M. D. R., Albuquerque, F. H. F. D., Quirós, J. T., \& Rodrigues, N. M. B. (2017). As diferenças em torno dos valores culturais: um estudo empírico a partir de entidades listadas em índices europeus. Revista Contabilidade e Controladoria, 9(1), 9-30. 
Santana, A. G., \& Klann, R. C. (2016). Conservadorismo Contábil e a adoção das IFRS: Evidências em empresas brasileiras familiares e não familiares. Enfoque: Reflexão Contábil, 35(1), 35-53.

Salter, S. B., \& Lewis, P. A. (2011). Shades of Gray: An empirical examination of Gray's model of culture and income measurement practices using 20-F data. Advances in Accounting, 27(1), 132-142.

Salter, S. B., \& Niswander, F. (1995). Cultural influence on the development of accounting systems internationally: A test of Gray's [1988] theory. Journal of International Business Studies, 26(2), 379-397.

Sarlo Neto, A., Rodrigues, A., \& Almeida, J. E. F. de (2010). Concentração de votos e acordo de acionistas: influências sobre o conservadorismo. Revista Contabilidade \& Finanças, 21(54), 6-22.

Schultz, J. J., \& Lopez, T. J. (2001). The impact of national influence on accounting estimates: Implications for international accounting standard-setters. The International Journal of Accounting, 36(3), 271-290.

Sudarwan, M., \& Fogarty, T. J. (1996). Culture and accounting in Indonesia: an empirical examination. The International Journal of Accounting, 31(4), 463-481.

Verma, S. (1998). Culture and politics in international accounting: An exploratory framework. Birkbeck College, School of Management and Organizational Psychology.

Watts, R. L. (2003). Conservatism in accounting part I: Explanations and implications. Accounting Horizons, 17(3), 207-221. 